\title{
Incorporação de resíduos da produção de fibras de sisal em argamassa: Efeitos nas propriedades físicas e mecânicas
}

\author{
Incorporation of waste from the production of \\ sisal fibers into mortar: Effects on physical \\ and mechanical properties
}

\author{
Leonardo de Souza Dias ${ }^{1}$, Alice Vitória Serafim Beserra ${ }^{2}$, Robson Arruda dos Santos ${ }^{2}$, \\ André Albino de Sousa ${ }^{2}$, Assis Barbosa de Lira Neto ${ }^{2}$, \\ Aurélia Emanoela de Freitas Gonçalves Landim ${ }^{2}$, Geovany Ferreira Barrozo ${ }^{2}$, \\ Cícero Joelson Vieira Silva ${ }^{2}$
}

\footnotetext{
${ }^{1}$ Universidade Federal do Rio Grande do Norte - UFRN, PEC, Av. Salgado Filho, 3000, CEP: 59078-970, Natal, RN, Brasil.

${ }^{2}$ Instituto Federal da Paraíba - IFPB, Rua José Antônio da Silva, 300, CEP: 58900-000, Cajazeiras, PB, Brasil. e-mail: leonardodiaspb@gmail.com, alicevitoriasb@outlook.com, robson.santos@ifpb.edu.br, andresousa.ec3@gmail.com, liraassis98@gmail.com, emanuelalandim@gmail.com, geovany.sh75@gmail.com, cjoelson@ymail.com
}

\section{RESUMO}

$\mathrm{Na}$ indústria da construção civil, buscam-se atualmente medidas mitigadoras dos impactos causados ao meio ambiente. Uma alternativa que vem ganhando espaço nos últimos anos diz respeito à utilização das fibras vegetais, que dentre os seus diversos tipos pode-se destacar as provindas do sisal, que apresentam forte relevância socioeconômica ao semiárido nordestino. Tendo em vista essa importância, o presente estudo teve como objetivo analisar os efeitos nas propriedades físicas e mecânicas que o beneficiamento a partir de resíduos provindos da produção de fibras de sisal promove em argamassa. Trata-se de um estudo experimental e quantitativo, sendo a pesquisa dividida em três etapas: levantamento teórico e conceitual; caracterização dos resíduos da fibra de sisal, agregado e aglomerante; e experimentação destrutiva e não destrutiva do composto cimentício. No que concerne a consistência da argamassa com adição de fibra, pode-se perceber que o filamento acaba atuando como uma rede que retém as partículas de agregados de maior granulometria, segregando assim uma pasta formada basicamente por cimento e água. Com relação à resistência à compressão e módulo de elasticidade, os corpos de prova acrescido de resíduos de fibras apresentaram uma redução quando comparados com os isentos da mesma, tendo como provável causa uma falha na compactação em decorrência da presença da fibra. Em contrapartida observou-se um ganho de $60 \%$ na resistência à tração aos 28 dias quando adicionada a fibra, pois esta atua distribuindo as tensões ao longo da peça, retardando o processo de fissuração e consequentemente o rompimento da estrutura.

Palavras-chave: compósitos cimentícios, resíduos, sustentabilidade.

\section{ABSTRACT}

In the civil construction industry, current alternatives are sought to mitigate the impacts caused to the environment. An alternative that is taking place in recent years concerns the use of vegetable fibers, which among the various types it is possible to highlight those from sisal, which have a strong socioeconomic relevance to the Northeastern semiarid. Given this importance, the present study aimed to analyze the effects on the physical and mechanical properties that the processing from wastes arising from the sisal fibers production promotes in mortar. It is an experimental and quantitative study, divided into three stages: theoretical and conceptual survey; characterization of sisal fiber, aggregate and binder; and destructive and non-destructive experimentation of the cementitious compound. About to the mortar consistency with addition of fiber, it can be seen that the filament ends up acting as a network that retains the particles of aggregates of greater granulometry, thus segregating a paste basically formed by cement and water. Regarding the compressive strength and 
elasticy modulus, the specimens plus fiber residues showed a reduction when compared to those exempt from it, with a probable cause of a failure in compaction due to the presence of the fiber. In counterpart, there was a $60 \%$ gain in tensile strength was observed at 28 days when the fiber was added, as it acts by distributing the stress throughout the part, delaying the cracking process and consequently breaking the structure.

Keywords: cementitious composites, waste, sustainability.

\section{INTRODUÇÃO}

O setor da construção civil apresenta-se como agente do desenvolvimento socioeconômico, sendo potencialmente capaz de promover subsídios que elevam o crescimento, tornando-o atraente aos investimentos e viabilizando o fortalecimento de outras estruturas de mercado dependentes, causando assim um efeito multiplicador de renda.

Em contrapartida a tais efeitos de desenvolvimento, estão os impactos negativos ao meio ambiente atrelados ao setor, causados principalmente pelo aumento da demanda por recursos naturais, pela transformação do meio, bem como pela geração de resíduos [1, 2]. Uma alternativa que vem sendo relevante para o enfrentamento dessa problemática é a utilização de resíduos e subprodutos industriais nos processos construtivos, caracterizando-se como uma ferramenta sustentável que auxilia na redução do consumo de recursos naturais, como também da massa residual de outras esferas produtivas [3 - 5]. Além disso, essa prática pode influenciar diretamente nos valores finais de uma obra, barateando os custos atrelados aos materiais convencionais substituídos por resíduos disponíveis em grande escala e diversidade.

Das diversas alternativas referentes à utilização de resíduos e subprodutos nos processos construtivos, pode-se mencionar o mercado das fibras vegetais. Esse ramo industrial gera resíduos aptos à aplicação em compósitos cimentícios, que quando comparados às demais fibras de origem sintética apresentam propriedades equivalentes ou até mesmo superiores $[6,7]$.

As fibras, sejam de origem vegetal ou sintética, apresentam-se como ferramenta no processo de fortalecimento de compostos cimentícios, agindo na transferência de cargas externas (tração) ao longo deste. Essas estruturas retardam a propagação de fissuras decorrente de solicitações por meio da absorção de energia, atuando como ponte, fazendo-se necessário uma carga superior à aderência entre a matriz e a fibra ou que exceda a resistência interna desta última para que assim exista ruptura [8 - 10].

Dentre os diferentes tipos de fibras, tem-se a produzida a partir do sisal (Agave Sisalana, família Agavaceai), espécie originária do México, com boa adaptação ao solo e ao clima árido [11]. Essas são extraídas a partir das folhas, representando de 3 a $5 \%$ do seu peso. Sua estrutura é composta de fibrilas ou microfibras constituídas basicamente de lignina, hemicelulose e celulose, principais compostos responsáveis pelas propriedades mecânicas e físicas da fibra. No que concerne seus aspectos econômicos, o mercado de fibras duras de sisal tem o Brasil como o maior produtor mundial, sendo os estados da Bahia, Rio Grande do Norte e Paraíba os maiores polos a nível nacional [12-14].

As fibras de sisal são empregadas em vários setores de produção, em esferas como o artesanato, a indústria têxtil, agrícola, farmacêutica, entre outros. No setor da construção civil, mesmo sendo uma prática antiga, a sua utilização tem se tornado recentemente um objeto de interesse na substituição de fibras sintéticas no processo de reforço em materiais poliméricos, como também em outros compostos cimentícios convencionais. Principalmente por se tratar de um produto advindo de fonte renovável, que fornece alta tenacidade, resistência à abrasão, além de possuir baixo custo, densidade relativamente pequena e pouco consumo de energia em sua produção $[12,15]$.

Alguns estudos evidenciam essas características na utilização de fibras de sisal em compostos construtivos. Ensaios realizados por Toledo Filho et al. [16] em traço de 1:1:0,4, com cimento Portland comum, finura da areia de 2,81, fração volumétrica da fibra de $2 \%$ e $3 \%$ e comprimento variando de $15 \mathrm{~mm}$ a $25 \mathrm{~mm}$, mostram um aumento na relação resistência à primeira fissura/ resistência a compressão, com uma magnitude de $22,5 \%$ para $2 \%$ de reforço. Lima et al. [17], com projeto de mistura de 1: 0,5: 0,4, sendo o ligante composto por $50 \%$ de cimento Portland CP V, $30 \%$ de metacaulim e $20 \%$ de cinzas volantes, agregado com finura de 1,79 e adição de $2 \%$ de resíduo de sisal com $50 \mathrm{~mm}$ de extensão, trazem resultados que alcançam um aumento de $24 \%$ da resistência à flexão, quando comparado à matriz de referência, valor próximo ao encontrado por Savastano Júnior e Pimentel [18], que em telhas de fibrocimento de sisal, produzidas com uma relação de materiais de 1:1,5:0,5, cimento Portland CPII-F 32, areia com finura de 2,12, um volume de fibras de $2 \%$ e comprimento entorno de $10 \mathrm{~mm}$, atingiram $15 \%$ a mais do padrão sem fibra. Outros autores como Izquierdo [3], Bonato et al. [19] e Bello et al. [20] apresentam também estudos com resultados positivos acerca do comportamento mecânico das estruturas enriquecidas com o material fibroso, sendo estes obtidos a 
partir de ensaios de tração e cisalhamento de uma matriz cimentícia reforçada com fibras de sisal.

Mesmo com tamanha aplicabilidade, a efetiva produção de pastas, argamassas e concretos reforçados com fibras de sisal ainda é escassa, esse fato é motivado, principalmente, como explica Lima e Toledo Filho [21], pela escassez de avaliações que predigam com precisão o desempenho mecânico de tais compósitos, para que assim os processos de planejamento e dimensionamento possam ser executados de forma segura e econômica.

Diante dos fatos supracitados, do vasto crescimento da construção civil e dos impactos ambientais vivenciados nos últimos anos, esse setor ver-se diante da necessidade de aperfeiçoar os processos construtivos, seja nos procedimentos técnicos ou na crescente utilização de materiais alternativos como ferramenta a viabilizar a redução de custos e/ou potencializar as propriedades inerentes aos seus produtos. Nessa perspectiva o presente estudo se objetiva a analisar os efeitos nas propriedades físicas e mecânicas da incorporação de resíduos provindos da produção de fibras de sisal em argamassa de cimento Portland típica da prática em obra, no intuito de fomentar a demanda por práticas que possibilitem a comunicação entre a redução dos impactos ambientais provindos do descarte de rejeitos industriais e a utilização de materiais de baixo custo, de alta disponibilidade e capazes de otimizar as características dos compósitos da construção civil.

\section{MATERIAIS E MÉTODOS}

Trata-se de um estudo experimental de natureza aplicada e com uma abordagem quantitativa, estabelecendo de forma sistematizada uma série de procedimentos, que auxiliam no desenvolvimento de informações acerca da utilização do material alternativo estudado, além de sintetizar e analisar esses dados para desenvolver uma explicação mais abrangente do fenômeno em questão [22].

O estudo foi realizado nas instalações do Instituto Federal de Educação, Ciência e Tecnologia da Paraíba, Campus Cajazeiras, sendo os procedimentos experimentais desenvolvidos nos laboratórios de Geotecnia e de Materiais de Construção, onde foram produzidos corpos de prova e analisados juntamente com as amostras dos resíduos das fibras de sisal, provenientes da etapa de corte do seu processamento, fornecidas pela empresa COSIBRA localizada no Município de Santa Rita, Paraíba.

\subsection{Caracterização dos materiais}

Os materiais a serem caracterizados foram selecionados segundo sua disponibilidade regional e uso recorrente nas obras locais, bem como pelo seu fornecimento por parte de empresas do ramo, no caso da fibra de sisal como anteriormente mencionado. De posse desses, os mesmos foram caracterizados por ensaios realizados em laboratório ou por meio de dados fornecidos por seus fabricantes.

O teor de umidade foi determinado fazendo-se inicialmente a preparação das do material, que se deu pelo corte manual das fibras, para sua regularização, em um comprimento de $30 \mathrm{~mm}$ organizando-as em cinco amostras, em que foram levadas à estufa por um período de 24 horas ou até massa constante, a uma temperatura de $60^{\circ} \mathrm{C}$, conforme Figura 1. Logo após o processo de secagem as fibras tiveram suas massas determinadas em uma balança analítica de precisão, obtendo-se a massa seca. Posteriormente os recipientes foram expostos ao ar, sendo esta a massa seca ao ar. O cálculo do teor de umidade das fibras foi realizado com base na NBR 7190 [23].

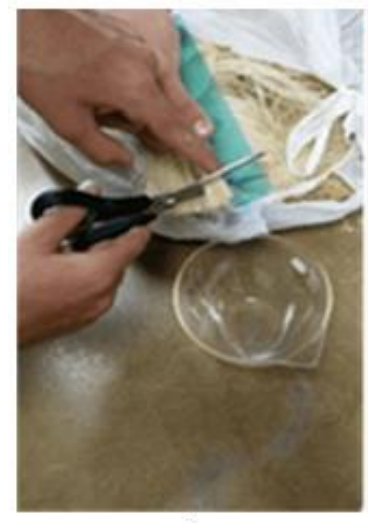

a)

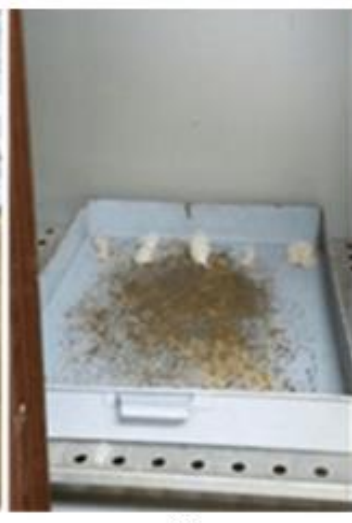

b)

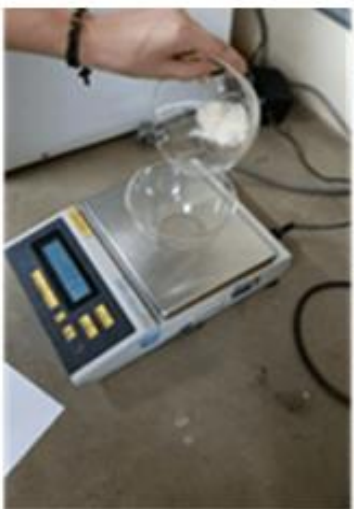

c)

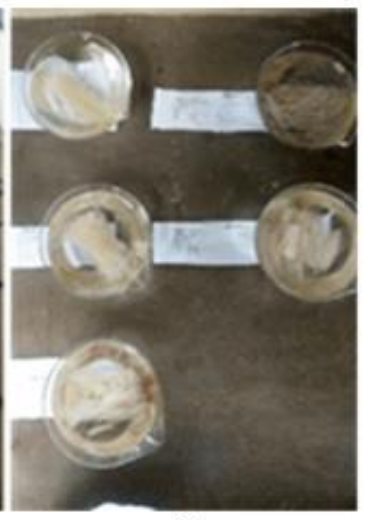

d)

Figura 1: Processo de preparação das amostras com seu (a) corte manual; (b) secagem em estufa; (c) determinação de suas massas; e (d) destinação as condições específicas de cada ensaio. 
A absorção de água das fibras se deu inicialmente pela preparação da amostra conforme ensaio anterior, sendo posteriormente um total de cinco amostras mergulhadas em água $\left(20^{\circ} \mathrm{C} \pm 2\right)$, determinando-se a massa úmida ao longo do tempo, com base na NBR 10024 [24], observada em intervalos de 5, 30, 60 e 120 minutos e a cada 24 horas até o sexto dia.

A densidade real $\left(\rho_{\text {real }}\right)$ e aparente $\left(\rho_{\text {aparente }}\right)$ foram determinadas através da adaptação dos ensaios da NBR 7190 [23]. Inicialmente fez-se o corte manual de cinco amostras da fibra em dimensões de $30 \mathrm{~mm}$, as quais foram separadas, rotuladas e submersas em água por um período de 24 horas. Uma vez decorrido esse intervalo de tempo e já com os poros saturados, os recipientes foram expostos ao ar e posteriormente pesados, sendo encontrada a massa saturada seca ao ar $\left(\mathbf{M}_{\text {sat }}\right)$. Logo após, as amostras foram colocadas em uma proveta com o volume inicial $\left(\mathrm{V}_{\mathrm{i}}\right)$ de água presente no recipiente previamente registrado e sequencialmente realizou-se a leitura do volume final $\left(\mathrm{V}_{\mathrm{f}}\right)$, correspondente a elevação da coluna de água dada pela inclusão da fibra no tubo. Em seguida secou-se o material em estufa por 24 horas ou até massa constante, a fim de obter a massa seca $\left(\mathrm{M}_{\mathrm{s}}\right)$. O cálculo dos parâmetros se deu por meio das Equações 1 e 2.

$$
\begin{aligned}
& \rho_{\text {real }}=\frac{M_{s}}{\left(V_{f}-V_{i}\right)-\left[\frac{M_{\text {sat }}-M_{s}}{\rho_{\text {agua }}}\right] M_{s}} \\
& \rho_{\text {aparente }}=\frac{M_{s}}{\left(V_{f}-V_{i}\right)}
\end{aligned}
$$

No que diz respeito à caracterização do agregado, realizou-se o ensaio para determinação da sua composição granulométrica de acordo com a NBR NM 248 [25], com curva apresentada na Figura 2, como também a sua massa específica real em conformidade à norma ME 194 [26]. Com relação ao aglomerante utilizou-se o cimento Portland do tipo CP II-Z 32, sendo suas características fornecidas pelo fabricante, como apresentado na Tabela 1.

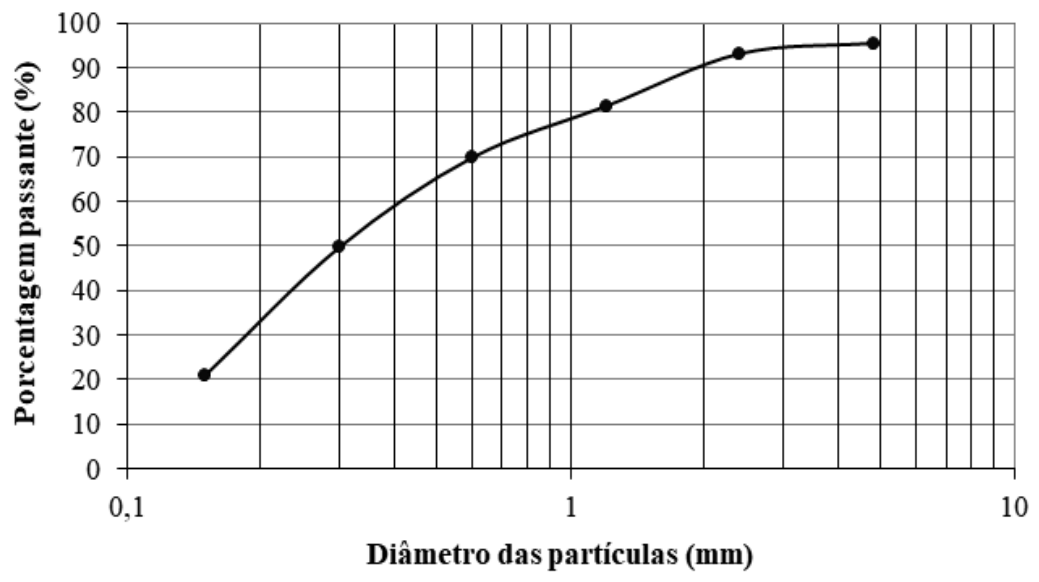

Figura 2: Distribuição granulométrica da areia.

Tabela 1: Caracterização do agregado e aglomerante.

\begin{tabular}{l|l|l}
\hline \multirow{2}{*}{ PARÂMETROS } & \multicolumn{2}{|l}{ RESULTADOS } \\
\cline { 2 - 3 } & AGREGADO & AGLOMERANTE \\
\hline Massa específica $\left(\mathrm{g} / \mathrm{cm}^{3}\right)$ & 2,59 & 3,02 \\
\hline Diâmetro máximo característico $(\mathrm{mm})$ & 4,80 & - \\
\hline Módulo de finura & 1,90 & - \\
\hline
\end{tabular}

Vale salientar que os ensaios seguiram os critérios mínimos de reprodução e os intervalos de aceitação dos resultados, procedendo-se com a repetição desses em caso de inconformidades com suas respectivas normativas. 


\subsection{Dosagem e Preparação das argamassas}

Os corpos de prova, um total de 188, foram moldados e curados de acordo com a NBR 7215 [27] e a NBR 5738 [28], respectivamente. Moldes cilíndricos foram utilizados (50 mm de diâmetro e $100 \mathrm{~mm}$ de altura). Já a cura se deu por imersão realizada em tanque d'água saturada em cal, local em que ficaram submersos das 24 horas após a moldagem até a realização dos seus ensaios específicos.

A dosagem empregada no estudo tomou como base o Caderno Técnico do Grupo Contrapiso [29], fazendo uso da relação 1:3 (Aglomerante: Agregado) que segundo este apresenta opção de preparo manual ou mecânico, além de ser um traço recorrente no mercado, o que diferencia da maioria dos trabalhos, como os anteriormente citados, que apresentam uma mistura com maior consumo de cimento em relação ao agregado ou a utilização de adições cimentantes [16 - 20]. A quantidade de água incorporada na mistura foi determinada executando-se traços isentos de fibra e com diferentes relações água/cimento com a finalidade de se obter uma consistência adequada a sua aplicação, seguindo as orientações da NBR 13276 [30], obtendo-se o fator a/c (água/cimento) de 0,70 .

No que se refere à porcentagem de adição de resíduos de fibras, foram utilizadas as proporções de: $0 \% ; 0,1 \% ; 0,4 \%$ e $0,5 \%$ em relação à massa de cimento. Traços pilotos de $0,8 \%, 0,9 \%$ e $1 \%$, foram executados na tentativa de empregar uma maior fração do resíduo e se aproximar ao tipicamente apresentado na literatura que circunda valores de $2 \%$ a $3 \%$, sendo esses descartados, uma vez que se mostraram com baixa trabalhabilidade, inviabilizando o processo de mistura em argamassadeira, sendo esse preparo executado conforme NBR 16541 [31].

As fibras adicionadas foram cortadas em um comprimento de $30 \mathrm{~mm}$, sendo que essa medida possibilitou uma melhor dispersão e trabalhabilidade da mistura na matriz cimentícia, principalmente quando comparada a dimensões maiores, como no caso de 50mm, como utilizada no trabalho de Lima et al. [17], além de que valores maiores, testados de forma preliminar, que se mostraram de difícil preparo em argamassadeira.

\section{3 Índice de Consistência das argamassas}

A consistência das argamassas foi determinada conforme a NBR 13276 [30], submetendo a mistura a quedas contínuas, promovida pela mesa para índice de consistência, e posteriormente medindo-se o diâmetro formado pelo material, sendo realizadas três medições em que duas dessas estivessem em posições perpendiculares. $\mathrm{O}$ valor final corresponde à média entre os resultados averiguados.

\subsection{Retenção de Água das argamassas}

A análise foi realizada tomando como referência a NBR 13277 [36]. Inicialmente a amostra foi preparada de acordo com a NBR 16541 [31], sendo posteriormente conduzida ao funil Buchner modificado contendo um papel filtro umedecido, ambos com massa previamente registrada. Após o preenchimento e adensamento do conjunto (funil/prato/papel filtro), a amostra foi rasada e submetida à sucção correspondente a coluna de 51 mm de mercúrio durante 15 minutos. Com o registro das massas solicitadas em norma mediante precisão de $0,1 \mathrm{~g}$, obteve-se o percentual de retenção de água.

\subsection{Absorção de Água por Capilaridade das argamassas}

O teste foi desenvolvido conforme os passos expressos na NBR 9779 [32], realizado com o um total de três repetições. Os corpos de prova testados, inicialmente levados à estufa, tiveram suas massas determinadas encontrando-se a massa seca e posteriormente submetidos a uma lâmina d'água, permanecendo em intervalos de tempo determinados em norma, obtendo-se assim a massa úmida. A se tratar de argamassa os intervalos utilizados seguiram a NBR 15259 [33], mais especificamente nos instantes de 10 min e 90 min. Logo após essa etapa realizou-se o rompimento por compressão diametral e registrou-se o comportamento da linha de água absorvida pela peça.

\subsection{Resistência à Compressão Axial e à Tração por Compressão Diametral das argamassas}

Os ensaios de resistência à compressão axial e à tração por compressão diametral foram executados de acordo com as normas NBR 13279 [34] e NBR 7222 [35], respectivamente. Nesses testes os corpos de prova foram moldados e submetidos à cura, conforme descrito anteriormente, e rompidos nas idades de 7, 14, 21 e 28 dias, além da avaliação aos 360 dias na tentativa de observar possíveis alterações no comportamento mecânico em idades avançadas, uma vez que se trata da adição de um material natural.

Para o ensaio por compressão diametral os corpos de prova foram submetidos à ruptura aos 28 dias em duas situações distintas: rompimento imediato depois de retirada do tanque, ainda saturados; e secos em 
estufa por um período de 24 horas ou até massa constante, no intuito de verificar o comportamento da fibra frente a sua solicitação mecânica, quanto à presença de água em sua estrutura. Vale ressaltar que para cada idade, proporção de adição e direção do carregamento, rompeu-se um número de quatro amostras (superior ao mínimo exigido nas referidas normas), totalizando 160 corpos de prova.

\subsection{Módulo de Elasticidade Dinâmico das argamassas}

Para realização do ensaio aos 28 dias determinou-se previamente a densidade de massa aparente dos corpos de prova, conforme NBR 13280 [37]. Com as superfícies superior e inferior limpas e lisas, aplicou-se o gel de contato e posteriormente posicionou-se os transdutores, registrando os valores apresentados no mostrador do equipamento Pundit Lab, sendo realizadas três leituras para cada quatro amostras por proporção conforme NBR 15630 [38]. O cálculo do módulo de elasticidade se deu como apresentado em norma, em que o Coeficiente de Poisson que assume valor de 0,2 para o ensaio.

\subsection{Análise Estatística}

Os dados tabulados foram apreciados por meio da ferramenta ANOVA, que permite fazer uma comparação entre múltiplos grupos, possibilitando com base no teste $\mathrm{F}$ estabelecer a aceitação ou rejeição da hipótese nula, em que $\mathrm{H}_{0}$ (hipótese nula) corresponde a igualdade entre as médias comparadas, complementando com o teste Tukey para avaliação da diferença significativa entre as médias. Utilizaram-se também os testes Bartlett e Shapiro-Wilk, no processo de caracterização dos dados quanto à normalidade e homogeneidade de variância, respectivamente. Vale ressaltar que se adotou o nível de significância de $5 \%$.

\section{RESULTADOS}

\subsection{Caracterização da Fibra}

A partir dos testes experimentais feitos com a fibra de sisal foi possível obter as suas características físicas, como teor de umidade, massa específica e absorção de água, conforme é apresentado na Tabela 2.

Tabela 2: Caracterização das propriedades físicas do resíduo da fibra de sisal.

\begin{tabular}{l|c|c|c|c}
\hline VALORES & $\begin{array}{c}\text { TEOR DE } \\
\text { UMIDADE (\%) }\end{array}$ & $\begin{array}{c}\text { MASSA ESPECÍFI- } \\
\left.\text { CA REAL (G/CM }{ }^{3}\right)\end{array}$ & $\begin{array}{c}\text { MASSA ESPECÍFICA } \\
\text { APARENTE (G/CM })^{3}\end{array}$ & $\begin{array}{c}\text { ABSORÇÃO DE } \\
\text { ÁGUA (\%) }\end{array}$ \\
\hline Média & 5,82 & 0,90 & 0,44 & 269,48 \\
\hline Desvio padrão & 3,82 & 0,41 & 0,24 & 12,93 \\
\hline Variância & 14,66 & 0,02 & 0,06 & 167,43 \\
\hline
\end{tabular}

O teor médio de umidade obtido de 5,82\% é considerado relativamente baixo quando se trata de fibras vegetais. Esse tipo de material, também denominado de lignocelulósicos, apresenta características hidrofílicas decorrente principalmente da presença de celulose não cristalizada e hemicelulose, o que propicia geralmente uma umidade na faixa de 8 a 12,5\% [39, 40]. Uma possível motivação pode decorrer da exposição da fibra ao clima regional, além do confinamento em laboratório durante os ensaios. O baixo percentual de umidade obtido é essencial para aplicação em um produto de durabilidade prolongada, como é o caso de compostos cimentícios [41].

Quanto aos resultados referentes às massas específicas real e aparente verificou-se, de acordo com a Tabela 2, valores de $0,90 \mathrm{~g} / \mathrm{cm}^{3}$ e $0,44 \mathrm{~g} / \mathrm{cm}^{3}$, respectivamente, mostrando-se ligeiramente abaixo aos dados presentes no trabalho de Pickering et al. [14] em que é atribuída ao sisal uma massa específica variando de 1,3 a $1,5 \mathrm{~g} / \mathrm{cm}^{3}$, ainda segundo esse autor, os resultados apresentados são amplamente variáveis, sendo bastante sensíveis a fatores com local do plantio e metodologia do ensaio. Essas características influem diretamente na resistência mecânica oferecida pela fibra, que de acordo com Motta [42], fibras vegetais tendem a possuir resistência diretamente proporcional à sua massa específica.

No que concerne à absorção de água, observou-se uma média de 269,48\%, como apresentado na Tabela 2, após 168 horas imersas em água. Esses valores estão próximos aos encontrados no trabalho de Machado [43], em que se empregou uma metodologia proposta por Toledo Filho et al. [16], obtendo um índice de capacidade de absorção de $240 \%$. Tal fato se deve ao seu arranjo estrutural e composição química, consti- 
tuído de subunidades celulares individuais denominadas de microfibras agrupadas por meio de lamela intercelular, possuindo também lacunas e lúmens, correspondentes a cavidades localizadas no eixo da fibra, levando a incidência de poros permeáveis [44].

\subsection{Consistência das argamassas}

Os dados obtidos para consistência das argamassas, acrescida com diferentes teores de fibras nas proporções anteriormente citadas, são apresentados na Tabela 3, com as médias estatisticamente distintas a nível de significância de $5 \%$ (valor-p <0,05).

Tabela 3: Consistência das argamassas por concentração de fibra de sisal.

\begin{tabular}{c|c}
\hline TEOR DE FIBRA & DIÂMETRO FINAL (MM) \\
\hline $0,0 \%$ & 260 \\
\hline $0,1 \%$ & 254 \\
\hline $0,4 \%$ & 237 \\
\hline $0,5 \%$ & 230 \\
\hline
\end{tabular}

De acordo com os dados apresentados é possível perceber que o acréscimo de fibras é inversamente proporcional ao diâmetro decorrente da queda pela mesa de consistência, em outras palavras o espalhamento é menor à medida que a proporção da mesma aumenta. Essa característica pode ser justificada pelo incremento da área superficial de molhagem em decorrência da adição do resíduo. Outro fator que corrobora para tal comportamento, assim como apresentado por Savastano Júnior e Agopyan [44], corresponde à absorção de água natural apresentada pelo material.

Baseado nos resultados dos testes pilotos para obtenção da consistência de diâmetro de $260 \mathrm{~mm}( \pm 5$ $\mathrm{mm}$ ), observou-se que o aumento da relação a/c proporciona, como esperado, uma segregação entre a pasta e as partículas de agregado, além de um comportamento de retenção dessas partículas pelas fibras, conforme apresentado na Figura 3, que retrata a atuação da fibra para relações de a/c maiores que 0,7, mais especificamente 0,9 .

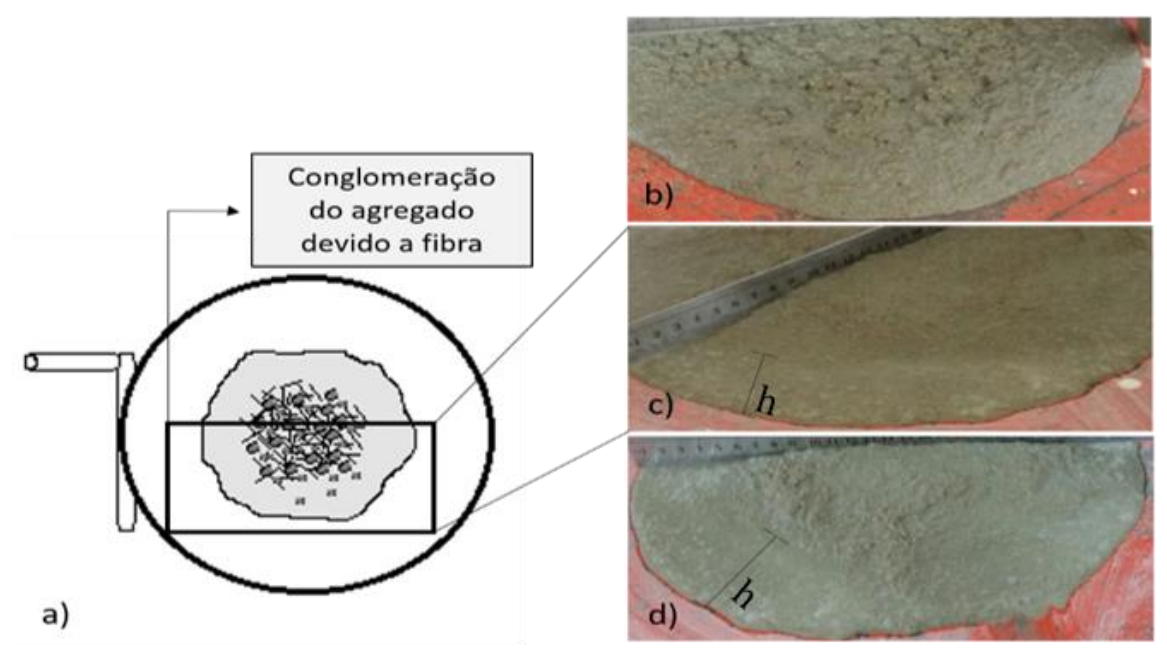

Figura 3: (a) Modelo do ensaio na mesa de consistência; (b) Consistência $0,1 \%$ de fibras (a/c=0,7); (c) Consistência $0,1 \%$ de fibras $(\mathrm{a} / \mathrm{c}=0,9)$; (d) Consistência $0,5 \%$ de fibras $(\mathrm{a} / \mathrm{c}=0,9)$.

A Figura 3 permite observar que a fibra acaba formando um efeito de contenção, principalmente dos agregados, agindo como uma rede que retém as partículas maiores conforme é ilustrado na imagem (a). Esse comportamento acarreta no processo de exsudação em que ocorre o escoamento de parte da mistura formada basicamente de cimento, água e partículas de agregado de baixa granulometria, assim como é apresentado nas imagens (c) e (d), em que o aumento do teor de fibras, para relações de a/c elevadas, provoca uma aglomeração dos agregados e um aumento da região h, intensificando a exsudação. Já o que ocorre na imagem (b), é uma retenção de uma mistura mais homogênea, sem a segregação de fases. 
Um reflexo do efeito de agregação provocado pelo emprego de fibras em compostos cimentícios diz respeito ao aumento da consistência da mistura. No entanto, assim como aborda Mehta e Monteiro [10], essa característica não expressa necessariamente a trabalhabilidade da mistura, podendo permanecer ainda em parâmetros aceitáveis os processos de moldagem e adensamento, que ainda podem permanecer satisfatórios.

\subsection{Retenção de água das argamassas}

Os valores referentes ao ensaio de retenção de água são apresentados na Figura 4, comparando a relação entre a porcentagem de água retida após sucção padrão determinada em norma e o teor de fibra adicionado (TF (Teor de Fibra) de 0\%, 0,1\%, 0,4\% e 0,5\%).

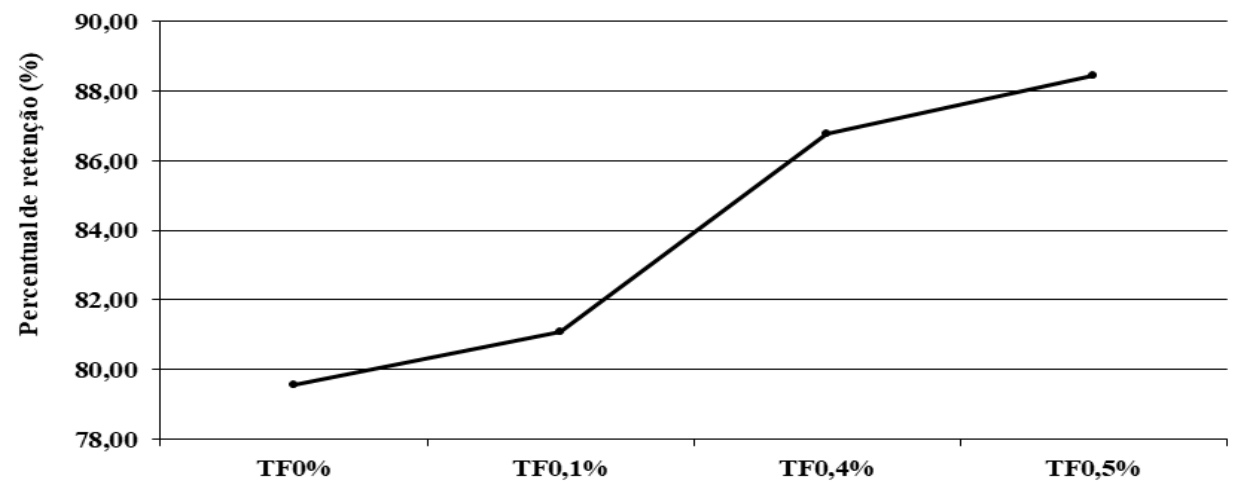

Figura 4: Retenção de água na argamassa em função do teor de fibra de sisal incorporado.

A partir da análise da Figura 4 é possível observar que o maior consumo de fibra implica diretamente no maior grau de retenção de água. Esse fato vai ao encontro às características intrínsecas das fibras que apresentam elevados valores e absorção provenientes da configuração estrutural da mesma, propriedade enfatizada nos estudos de Toledo Filho et al. [45], e que foram experimentalmente encontradas e apresentadas na Tabela 2.

A retenção em argamassa é uma importante característica visto, que a perda da água de amassamento pode comprometer os processos de hidratação do aglomerante, como também influenciar outras características da argamassa entre elas a consistência. A Figura 5 a seguir apresenta uma correlação entre os ensaios de retenção de água e de consistência em função do teor de fibra incorporado.

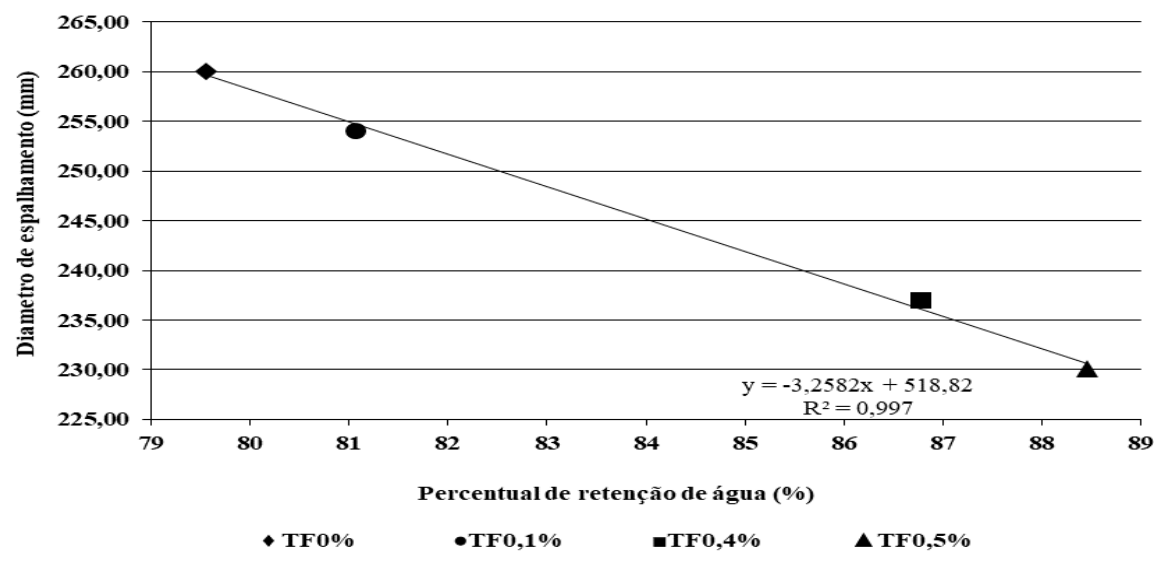

Figura 5: Correlação entre a retenção e consistência em função do teor de fibra.

A linearidade inversa, com correlação $\mathrm{R}^{2}$ de 0,997 , entre a retenção e o espalhamento da mistura vão mais uma vez ao encontro às propriedades naturais da fibra e de suas implicações nos comportamentos anteriormente mencionados. Essa associação de características (retenção e consistência) representa o papel de 
dupla retenção que a fibra oferece, tanto sob o aspecto absorvente quanto físico ao agir como uma malha que leva a conglomeração de partículas.

Vale ressaltar que, embora a retenção de água apresente uma relação crescente frente ao teor de fibra, esse comportamento não necessariamente pode ser julgado como positivo, já que uma das possíveis motivações para o aumento da retenção é a absorção da água pelas fibras, podendo resultar em alterações análogas àquelas decorrentes da ausência de água na mistura.

\subsection{Resistência mecânica à compressão axial das argamassas}

Os dados referentes à resistência a compressão, em que os corpos de prova foram submetidos a um carregamento axial, são apresentados na Figura 6 abaixo, correlacionando o tempo de cura de 7, 14, 21, 28 e 360 dias e teor de fibra adicionado (TF (Teor de Fibra) de 0\%, 0,1\%, 0,4\% e 0,5\%).

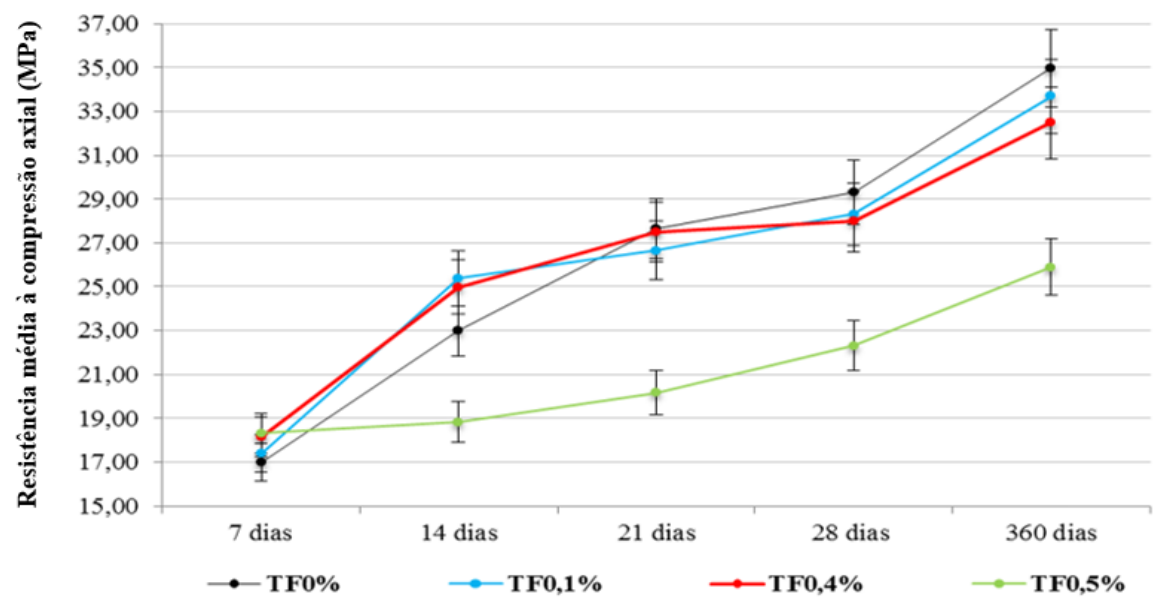

Figura 6: Resultados da resistência média à compressão axial das argamassas em função da idade e com diferentes teores de fibras de sisal.

Conforme apresentado na Figura 6, observa-se que os corpos de prova com fibras de sisal apresentaram redução na resistência à compressão quando comparados à mistura de referência, verificando essa constância de resistência até idades mais avançadas como no caso de 360 dias, comportamento também observado por Santos, Fontes e Lima [46]. Em relação ao teste estatístico, salvo os resultados de 7 dias com valor-p > 0,05 , todos os demais apresentaram valor $-\mathrm{p}<0,05$. Com relação ao teste Tukey, apenas as combinações com a proporção de $0,5 \%$ e após os 7 dias se mostraram com diferença significativa entre os grupos.

Vale destacar que a concentração de fibras na matriz cimentícia influencia diretamente a redução da resistência à compressão (valor-p < 0,05). Como é o caso da porcentagem de $0,5 \%$, que apresentou o menor desempenho entre as demais. Segundo Toledo Filho et al. [47], esse fato pode ter como causa o adensamento comprometido que o aumento da fração de fibras acarreta na mistura. Tendo como agravante também a propriedade de absorção que a fibra de sisal oferece, conforme apresentado na Tabela 2. Assim como Savastano Júnior e Agopyan [44] constataram em algumas fibras vegetais, essa característica pode levar a um acúmulo de água na zona de transição entre a fibra e a matriz de cimento, que consequentemente trará uma maior porosidade da região em seu estado endurecido, o que provocará pontos de fragilidade, suscetíveis ao rompimento quando submetidos à solicitação.

Além das motivações supracitadas, outro fator que pode ocorrer e explicar esse comportamento diz respeito a aglomeração de fibras entre si que geram bolsões nas amostras (enovelamento de fibras), criando espaços frágeis ocasionando concentração de tensões e facilitando a ruptura, efeito observado nas dispersões dos resultados apresentados na Figura 6, que indica um material não homogêneo, resultante da distribuição das fibras em adição.

\subsection{Resistência mecânica à tração por compressão diametral}

Os resultados do ensaio de resistência à tração por compressão diametral são apresentados na Figura 7, estando presentes as porcentagens de fibras de sisal adicionadas à mistura e suas correspondentes resistências 
médias nos intervalos de 7, 14, 21, 28 e 360 dias, como também aos 28 dias no estado seco.

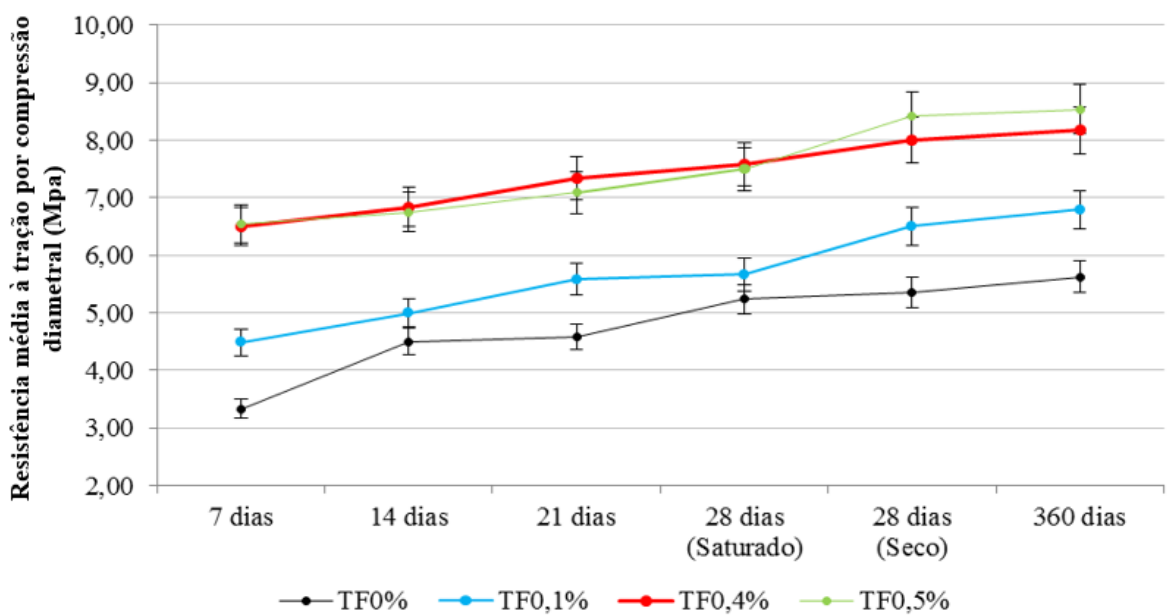

Figura 7: Resultados da resistência à tração por compressão diametral das argamassas em função da idade e com diferentes teores de fibras de sisal, como também aos 28 dias no estado seco.

A análise da Figura 7 permite observar que a adição de fibras de sisal aumenta a resistência média à tração consideravelmente (valor - $\mathrm{p}<0,05$ ). Essa característica é perceptível logo aos sete primeiros dias, quando comparado à mistura de referência, em que se registrou um aumento de 96,37\% entre as concentrações de $0,0 \%(2,2 \mathrm{MPa})$ e $0,5 \%$ (4,32 MPa) de fibras. Vale ressaltar que pelo teste de Tukey todas as médias se mostraram significativamente diferentes, salvo as combinações entre os traços de $0,4 \%$ e $0,5 \%$.

Essa influência significativa da resistência à tração pode ser provocada pelas características geométricas e pela textura superficial oferecidas pelas fibras de sisal. Segundo Monteiro et al. [48] a rugosidade que os compostos fibrosos possuem podem ajudar na adesão entre esses e a matriz, que ao ser submetida a esforços de tração ou flexão, assim como mencionado, a fibra atua como uma espécie de ponte entre as microfissuras iniciais distribuindo as tensões ao longo da peça, aumentando o seu reforço pós-físsuração, como pode ser observado na Figura 8.

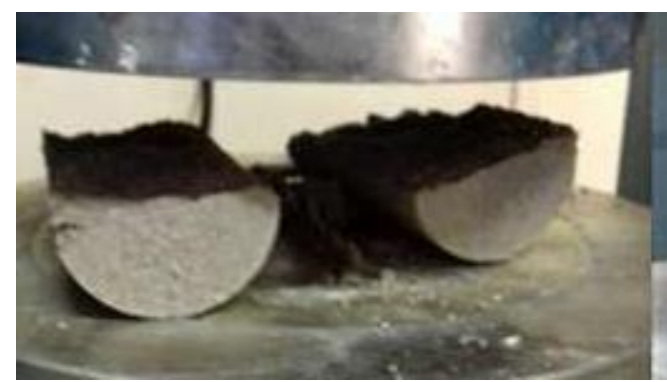

(a)

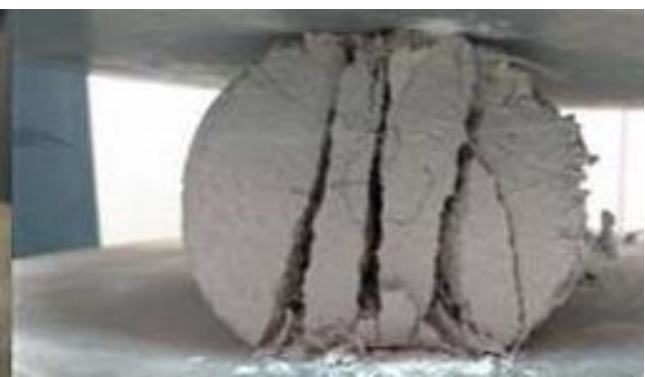

(b)

Figura 8: Rompimento diametral dos corpos: (a) Mistura com 0,0\% de fibra; ( b) Mistura com 0,4\% de fibra.

A fissuração em um corpo de prova submetido à carregamento impede que os esforços gerados sejam distribuídos, ocorrendo uma concentração das tensões principalmente nas extremidades da fissura, esse processo se estende até que se chegue a uma intensidade que leve à ruptura da estrutura [49]. Na Figura 8b, observa-se que as fibras inibem a confluência dessas tensões o que promove múltiplas fissuras, e para que ocorra a sua abertura é necessária uma quantidade de energia maior que a utilizada nos corpos isentos de fibra, como verificado nos resultados da tração na Figura 7. Já na Figura 8a, verifica-se fissuração concentrada com uma única linha de ruptura (mistura referência).Esse comportamento de múltiplas fissuras também foi verificado nos estudos de Silva et al. [9], o mesmo sob um foco microestrutural, observou que as fibras de sisal, conseguiram acomodar as tensões dentro da região de resposta elástica do compósito, inibindo as fissuras iniciais e levando à redistribuição das tensões proveniente da energia absorvida, motivando o surgimento de várias linhas de ruptura.

Outra característica importante a se observar diz respeito às diferenças nos valores da tração aos 28 
dias entre os corpos de prova secos e saturados (valor-p < 0,05), como apresentado na Figura 7. Nota-se um relativo aumento na resistência dos corpos de prova secos, todos com adição de fibras. Esse comportamento pode ocorrer devido à aderência das fibras à matriz cimentícia que é fragilizada em decorrência da saturação dos capilares presentes no material, desencadeando uma ruptura por deslizamento como pode ser visualizado na Figura 9 a, em que as fibras se mantêm íntegras no que diz respeito as suas condições superficiais. Em contrapartida o processo de secagem promove um aumento do número de fibras que apresentaram ruptura ao longo de sua estrutura observado na Figura 9 b, potencializando a resposta do material à tração direta.

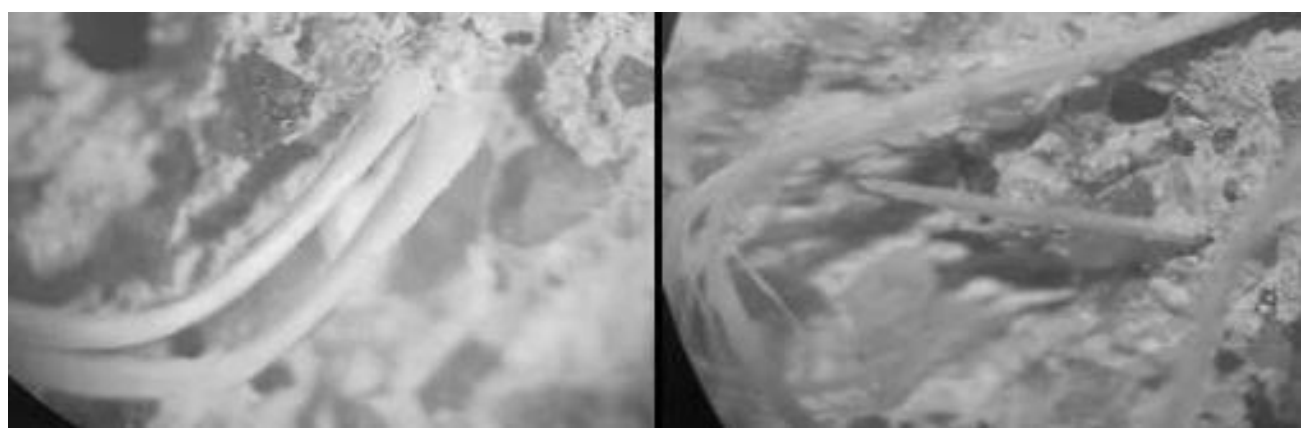

(a) (b)

Figura 9: Superfície das fibras após o rompimento do corpo de prova em estado: (a) saturado; (b) seco.

Esse comportamento interfacial das amostras é um resultado da baixa adesão química da fibra de sisal aos compostos cimentícios, assim como é apresentado por Li et al. [50]. Além disso, a capacidade de absorção de água e o caráter hidrofílico da fibra podem levar à formação de uma lâmina de líquido sobre sua superfície que favorece a perda de contato físico com a matriz, podendo ocasionar uma ruptura por deslizamento total ou parcial.

\subsection{Absorção de água por capilaridade das argamassas}

Os resultados obtidos no ensaio de absorção de água por capilaridade são apresentados na Tabela 4, verificando-se uma pequena redução nos valores referentes aos corpos de prova com fibras, fenômeno acentuado na comparação entre as amostras de $0,0 \%$ e $0,1 \%$ de adição, constatando-se uma variação de três pontos percentuais no índice médio de absorção nos 10 primeiros minutos. Essa diferença é pouco significativa, como apresentado no teste estatístico com valor-p > 0,05, esse comportamento pode indicar que a fibra de sisal agiu na obstrução inicial dos poros permeáveis da mistura, proporcionando uma barreira de absorção nos primeiros instantes [51, 52].

Tabela 4: Resultados médios de índice de absorção por capilaridade das argamassas com diferentes teores de fibra de sisal.

\begin{tabular}{l|c|c|c|c}
\hline TEOR DE FIBRA & C10 $\min (\%)$ & VARIÂNCIA C10 $\min$ & C90 $\boldsymbol{m i n}(\%)$ & VARIÂNCIA C90 $\min$ \\
\hline $0,0 \%$ & 10,87 & 0,00115 & 26,16 & 0,00460 \\
\hline $0,1 \%$ & 7,98 & 0,00109 & 23,44 & 0,00291 \\
\hline $0,4 \%$ & 9,85 & 0,00097 & 16,14 & 0,00063 \\
\hline $0,5 \%$ & 9,51 & 0,00027 & 22,76 & 0,00022 \\
\hline
\end{tabular}

Ao analisar os índices de absorção nos corpos de prova, nos instantes ensaiados, esses apresentam valores similares, com pouca variação nas diferentes proporções de fibra empregada, com ressalva a porcentagem de $0,4 \%$ de sisal aos $90 \mathrm{~min}$, essa pouca diferença significativa entre as médias é confirmada pelo teste Tukey para todas as combinações entre os grupos. Essa uniformidade também é apresentada nas linhas de água proveniente da absorção, como mostrado nas imagens da Figura 10. 


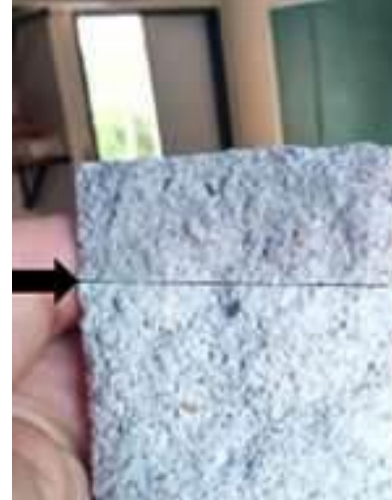

(a)

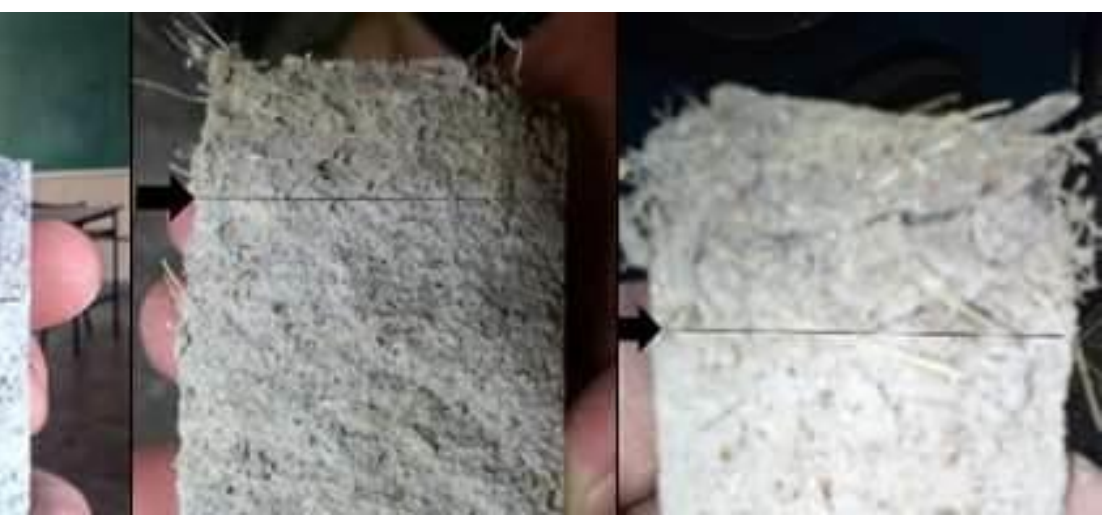

(b) (c)

Figura 10: Linha da absorção d'água: (a) Mistura com 0,0\% de fibra; (b) Mistura com 0,1\% de fibra; (c) Mistura com $0,5 \%$ de fibra.

Condizente com os valores de absorção presentes na Tabela 4 em que apresentam pouca variação, as linhas de absorção de corpos com ou sem fibras se comportam de maneira bastante similar, como é observado na Figura 10, com uma elevação da água absorvida aproximadamente uniforme em sua extensão, sem concentração ou picos.

Esse comportamento observado, em que os maiores teores de fibra proporcionaram um menor valor de absorção e que a amostra de referência possui o maior índice, vai ao encontro ao que Borges et al. [6] determinou em seus estudos aplicando fibras em concreto, entre elas o sisal. Segundo o mesmo, a porosidade total do compósito é geralmente aumentada, no entanto isso não necessariamente implica em uma maior permeabilidade, uma vez que para tal fato ocorrer deve existir uma interconectividade entre os poros da matriz, que por sua vez pode ter sido reduzida com a presença das fibras, além da possível redução das microfissuras internas, uma característica importante para argamassa a depender de sua aplicação.

\subsection{Módulo de elasticidade dinâmico por propagação de onda ultrassônica das argamassas}

Os valores obtidos no ensaio são apresentados na Figura 11 em função do teor de fibra incorporado. No que diz respeito à análise estatística verificou-se que os resultados possuem $95 \%$ de confiança com valor-p menor que 0,05 (valor-p < 0,05), além de diferença significativa entre todas as médias dada pelo teste Tukey.

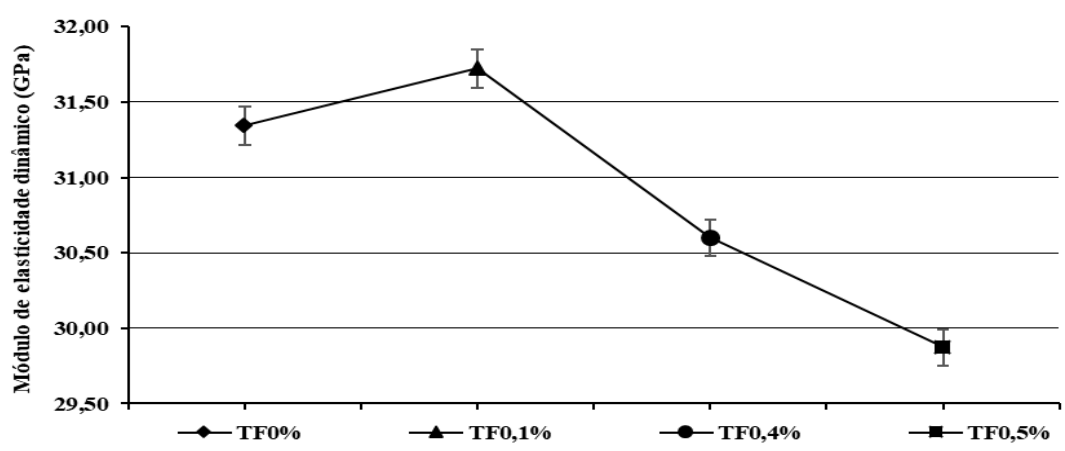

Figura 11: Módulo de elasticidade dinâmico das argamassas em função do teor de fibras de sisal incorporado.

A partir da Figura 11 é possível observar que a adição de fibra, em geral, levou a redução do módulo de elasticidade, com exceção da proporção de $0,1 \%$, chegando a uma redução de $4,66 \%$ para o teor de fibra incorporado de $0,5 \%$, o que pode levar a um melhor desempenho em aplicações como revestimentos que necessitam apresentar a capacidade de deforma-se sob a ação de tensões. Essa redução também foi observada nos estudos de Colonetti e Godinho [53] e Borges et al. [6], que realizaram o ensaio de resistência à compressão com o emprego de corpos de prova contendo a amostra de concreto, obtendo uma queda de $15,9 \%$ com a $0,3 \%$ de fibra e $16,60 \%$ para $0,5 \%$ do material, respectivamente.

Esse comportamento vai ao encontro às características mecânicas obtidas para o ensaio de compressão axial, como o observado na Figura 12, apresentado a correlação entre o desempenho mecânico sob solicitação axial e os valores de módulo de elasticidade, ambos aos 28 dias. 


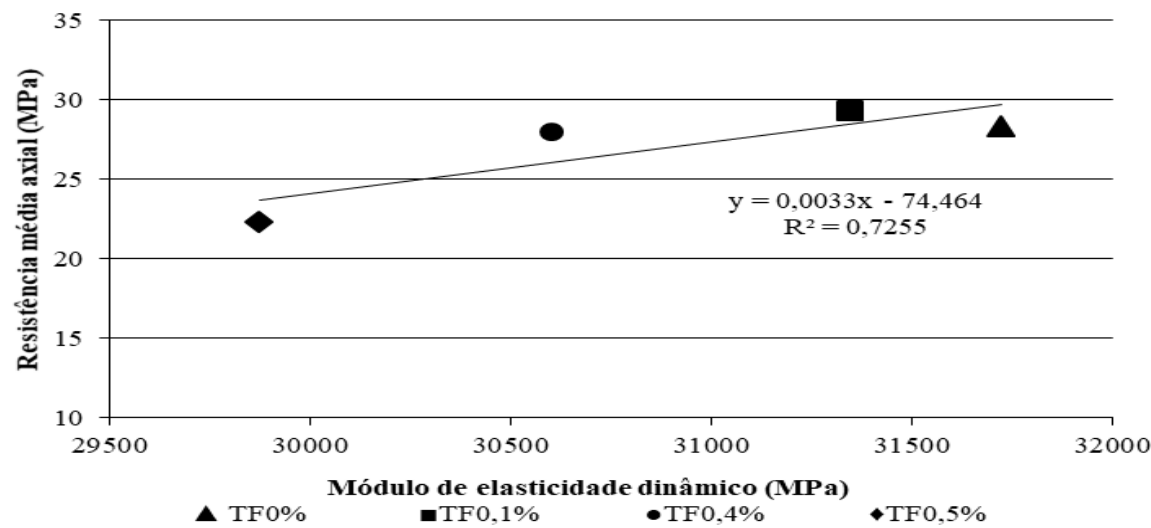

Figura 12: Correlação entre o módulo de elasticidade e resistência à compressão das argamassas em função do teor de fibra de sisal.

O comportamento linear positivo da reta de tendência indica a correlação diretamente proporcional entre as propriedades, com $\mathrm{R}^{2}$ de 0,7255 resultante da proporção de $0,1 \%$ de fibra incorporada que ao observar a curva na Figura 12 apresenta-se como o ponto de maior variação.

Essa relação vai ao encontro às observações da literatura no que diz respeito ao comportamento elástico de um composto cimentício, sendo o módulo de elasticidade uma correspondente da deformabilidade e rigidez da mistura, que por sua vez possui ligação intrínseca com a capacidade de resistência às solicitações $[47,54]$. Como já mencionado, a adição de fibra pode comprometer processos importantes de produção e endurecimento da argamassa, como seu adensamento e a absorção de água de amassamento, levando a alterações na homogeneidade da matriz e consequentemente influenciando no desempenho da mesma.

\section{CONCLUSÕES}

A utilização do resíduo da fibra de sisal de $30 \mathrm{~mm}$ de comprimento se mostra satisfatório no emprego de argamassas, principalmente em teores de até $0,4 \%$ da massa do cimento, uma vez que até essa faixa ganhos no comportamento mecânico foram notados sem o comprometimento significativo da resistência a compressão, em comparação ao teor de $0,5 \%$. De modo geral, foi possível observar que o resíduo intervém na qualidade e desempenho das amostras, que de maneira específica se pode concluir que:

- No estado fresco, o acréscimo do material fibroso na matriz cimentícia reduz o diâmetro de espalhamento da argamassa, uma vez que o sisal retém as partículas de agregados de maior granulometria além de absorver água, no entanto, essa característica não necessariamente representa perdas significativas de sua trabalhabilidade, já que não impossibilita o manuseio e moldagem da mistura. Além disso, o aumento no teor de fibra levou a uma maior retenção de água na argamassa, o que pode ser consequência das características absorventes da adição.

- No estado endurecido, o aumento das proporções de fibra provocou uma redução da resistência à compressão axial e do módulo de elasticidade nas amostras, no entanto, é válido destacar o significativo ganho de desempenho a níveis de resistência à tração por compressão diametral, o que torna as argamassas com adição de fibras vegetais mais eficientes quando comparadas a argamassa de referência, possuindo assim um potencial de aplicação em matrizes cimentícias que necessitam de resistência a esse tipo de solicitação. Além disso, pode-se ressaltar que mesmo a fibra sendo um material de propriedade hidroscópica, sua variação não acarretou alterações significativas na absorção dos corpos de prova estudados.

Tendo em vista a utilização de fibras vegetais provindas da planta Agave Sisalana e sua posterior aplicação a um compósito cimentício que requer durabilidade prolongada, é fundamental uma análise referente à biodegradação da fibra neste meio em situação de serviço e condições agressivas (Agentes agressivos, condições de temperatura elevadas, entre outras). Visto que a interação da fibra vegetal com o meio alcalino presente nos compósitos cimentícios pode acelerar o seu processo de biodegradação, devido principalmente à migração do hidróxido de cálcio para os lúmens e as paredes da fibra. 


\section{BIBLIOGRAFIA}

[1] PIACENTINI, P., "Brasil não consegue dar o destino adequado para resíduos", Ciência e Cultura, v. 70, n. 2, Pp. 13-15, 2018.

[2] LAM, P.T.I., YU, A.T.W., WU, Z., et al., "Methodology for upstream estimation of construction waste for new building projects", Journal of Cleaner Production, v. 230, pp. 1003-1012, 2019.

[3] IZQUIERDO, I.S., Utilização de pós residuais e fibra de sisal em blocos de concreto, Tese de D. Sc, USP, São Paulo, SP, 2015.

[4] LI, Z., LIU, Z., YAN, S. et al., "Effect of freeze-thaw cycles on mechanical and porosity properties of recycled construction waste mixtures", Construction and Building Materials, v. 210, pp. 347-363, 2019.

[5] BRASILEIRO, L.L., MATOS, J.M.E., "Revisão bibliográfica: reutilização de resíduos da construção e demolição na indústria da construção civil”, Cerâmica, v. 61, n. 358, pp. 178-189, 2015.

[6] BORGES, A.P.S.N., MOTTA, L.A.C., PINTO, L.B., "Estudo das propriedades de concretos com adição de fibras vegetais e de polipropileno para uso em paredes estruturais", Revista Matéria, v. 24, n. 2 , e12364, 2019.

[7] SILVA, F.A., MOBASHER, B., TOLEDO FILHO, R.D., "Cracking mechanisms in durable sisal fiber reinforced cement composites", Cement and Concrete Composites, v. 31, pp. 721-730, 2009.

[8] PEREIRA, M.V., FUJIYAMA, R., DARWISH, F., et al., "On the Strengthening of Cement Mortar by Natural Fibers", Materials Research, v.18, n.1, pp.177-183, 2015.

[9] BRAZ, M.C.A., NASCIMENTO, F.B.C., "Concreto reforçado com fibras de aço", Ciências exatas e tecnológicas, v.3, n.1, pp. 43-56, 2015.

[10] MEHTA, P.K., MONTEIRO, P.J.M., Concreto - Microestrutura, Propriedades e Materiais. 2 ed., São Paulo, IBRACON, 2014.

[11] BRASIL, Preços em alta favorecem produção de sisal no Semiárido. Portal Brasil, 2016.

[12] MELO, K.M., SANTOS, T.F., SANTOS, C.M.S., et al., "Study of the reuse potential of the sisal fibers powder as a particulate material in polymer composites", Journal of Materials Research and Technology, v. 8, pp. 4019-4025, 2019.

[13] MARTIN, A.R., MARTINS, M.A., MATTOSO, L.H.C., et al., "Caracterização Química e Estrutural de Fibra de Sisal da Variedade Agave sisalana”, Polímeros: Ciência e Tecnologia, v. 19, n.1, pp. 40-46, 2009. [14] PICKERING, K.L., EFENDY, M.G.A., LE, T.M., et al., "A review of recent developments in natural fibre composites and their mechanical performance", Composites Part A: Applied Science and Manufacturing, v. 83, pp. 98-112, 2016.

[15] JOSEPH, K., TOLEDO FILHO, R.D., JAMES, B., et al., “A review on sisal fiber reinforced polymer composites", Revista Brasileira de Engenharia Agrícola e Ambiental, v.3, n.3, pp. 367-379, 1999.

[16] TOLEDO FILHO, R.D., ENGLAND, G.L., GHAVAMI, K., “Comportamento em compressão de argamassas reforçadas com fibras naturais. Relação tensão-deformação experimental e processo de fratura”, Revista brasileira de engenharia agrícola e ambiental, v. 1, n. 1, pp. 79-88, 1997.

[17] LIMA, P.R.L., SANTOS, R.J., FERREIRA, S.R., et al., "Characterization and treatment of sisal fiber residues for cement-based composite application”, Engenharia Agrícola, v. 34, n. 5, pp. 812-825, 2014.

[18] SAVASTANO JÚNIOR, H., PIMENTEL, L.L., "Viabilidade do aproveitamento de resíduos de fibras vegetais para fins de obtenção de material de construção", Revista Brasileira de Engenharia Agrícola e Ambiental, v. 4, n. 1, pp. 103-110, 2000.

[19] BONATO, M.M., PORTELLA, K.F., BRAGANÇA, M.D.O.G.P., et al., "Photocatalytic mortars and concretes with addition of coconut and sisal fibers to reduce environmental impacts of pollutant gases", Cerâmica, São, v. 60, pp. 537-545, 2014.

[20] BELLO, C.B.C., BOEM, I., CECCHI, A., et al., "Experimental tests for the characterization of sisal fiber reinforced cementitious matrix for strengthening masonry structures", Construction and Building Materials, v. 219, pp. 44-55, 2019.

[21] LIMA, P., TOLEDO FILHO, R.D., "Uso de metacaulinita para incremento da durabilidade de compósitos à base de cimento reforçados com fibras de sisal", Ambiente Construído, v. 8, n.4, pp. 7-19, 2008. [22] LAKATOS, E.M., MARCONI, M.A., Metodologia do trabalho científico, 6 ed., São Paulo, Atlas, 2001. [23] ASSOCIAÇÃO BRASILEIRA DE NORMAS TÉCNICAS - ABNT - ABNT. NBR NM 7190: Projeto de estruturas de madeira. Rio de Janeiro, 1997.

[24] ASSOCIAÇÃO BRASILEIRA DE NORMAS TÉCNICAS - ABNT. NBR NM 10024: Chapa dura de fibra de madeira - Requisitos e métodos de ensaio. Rio de Janeiro, 2012.

[25] ASSOCIAÇÃO BRASILEIRA DE NORMAS TÉCNICAS - ABNT. NBR NM 248: Agregados - Determinação da composição granulométrica. Rio de Janeiro, 2003.

[26] DEPARTAMENTO NACIONAL DE ESTRADAS DE RODAGEM - DNER. ME 194: Agregado- Determinação da massa específica de agregados miúdos por meio do frasco Chapman. Rio de Janeiro, 1998. [27] ASSOCIAÇÃO BRASILEIRA DE NORMAS TÉCNICAS - ABNT. NBR 7215: Cimento Portland Determinação da resistência à compressão. Rio de Janeiro: ABNT, 2019. 
[28] ASSOCIAÇÃO BRASILEIRA DE NORMAS TÉCNICAS - ABNT. NBR 5738: Concreto -

Procedimento para moldagem e cura de corpos de prova. Rio de Janeiro: ABNT, 2015.

[29] SISTEMA NACIONAL DE PESQUISA DE CUSTOS E ÍNDICES DA CONSTRUÇÃO CIVIL. Cadernos de técnicos de composições para: contrapiso, contrapiso acústico e contrapiso autonivelante. v. 007. Grupo Contrapiso, 2015.

[30] ASSOCIAÇÃ̃O BRASILEIRA DE NORMAS TÉCNICAS - ABNT. NBR 13276: Argamassa para assentamento e revestimento de paredes e tetos - Preparo da mistura e determinação do índice de consistência. Rio de Janeiro: ABNT, 2016.

[31] ASSOCIAÇÃO BRASILEIRA DE NORMAS TÉCNICAS - ABNT. NBR NM 16541: Argamassa para assentamento e revestimento de paredes e tetos - Preparo da mistura para a realização de ensaios. Rio de Janeiro, 2016.

[32] ASSOCIAÇÃO BRASILEIRA DE NORMAS TÉCNICAS - ABNT. NBR 9779: Argamassa e concreto endurecidos - Determinação da absorção de água por capilaridade. Rio de Janeiro: ABNT, 2012.

[33] ASSOCIAÇÃO BRASILEIRA DE NORMAS TÉCNICAS - ABNT. NBR 15259: Argamassa para assentamento e revestimento de paredes e tetos - Determinação da absorção de água por capilaridade e do coeficiente de capilaridade. Rio de Janeiro: ABNT, 2005.

[34] ASSOCIAÇÃO BRASILEIRA DE NORMAS TÉCNICAS - ABNT. NBR 13279: Argamassa para assentamento e revestimento de paredes e tetos - Determinação da resistência à tração na flexão e à compressão. Rio de Janeiro: ABNT, 2005.

[35] ASSOCIAÇÃO BRASILEIRA DE NORMAS TÉCNICAS - ABNT. NBR 7222: Concreto e argamassaDeterminação da resistência à tração por compressão diametral de corpos de prova cilíndricos. Rio de Janeiro: ABNT, 2011.

[36] ASSOCIAÇÃO BRASILEIRA DE NORMAS TÉCNICAS - ABNT. NBR NM 13277: Argamassa para assentamento e revestimento de paredes e tetos - Determinação da retenção de água. Rio de Janeiro, 2005.

[37] ASSOCIAÇÃO BRASILEIRA DE NORMAS TÉCNICAS - ABNT. NBR NM 13280: Argamassa para assentamento e revestimento de paredes e tetos - Determinação da densidade de massa aparente no estado endurecido. Rio de Janeiro, 2005.

[38] ASSOCIAÇÃO BRASILEIRA DE NORMAS TÉCNICAS - ABNT. NBR NM 15630: Argamassa para assentamento e revestimento de paredes e tetos - Determinação do módulo de elasticidade dinâmico através da propagação de onda ultrassônica. Rio de Janeiro, 2008.

[39] PAULA, P.G., Formulação e caracterização de compósitos com fibras vegetais e matriz termoplástica. Dissertação de M. Sc, UENF, Rio de Janeiro, RJ, Brasil, 2011.

[40] CARASCHI, J.C., LEAO, A., RAMOS, U.M., "Compósitos biodegradáveis de polihidroxibutirato

(PHB) reforçado com farinha de madeira: propriedades e degradação", Acta Scientiarum. Technology, v. 24, pp. 1609-1614, 2002.

[41] SALAZAR, V.L.P., Estudo da biodegradação das fibras de coco e de sisal visando às aplicações na indústria automotiva. Tese de D. Sc, UNESP, Botucatu, SP, Brasil, 2005. [42] MOTTA, L. A. C.

Caracterização de Fibras curtas empregadas na construção Civil, São Paulo, EPUSP, 2007.

[42] MOTTA, L.A.C. Caracterização de Fibras curtas empregadas na construção Civil, São Paulo, EPUSP, 2007.

[43] MACHADO, C.X.B., Caracterização mecânica de compósitos de matriz cimentícia contendo resíduos de construção e demolição (RCD) reforçados com fibra de sisal. Dissertação de M. Sc, ISEL, Lisboa, Portugal, 2014.

[44] SAVASTANO JÚNIOR, H., AGOPYAN, V., "Transition zone studies of vegetable fibre-cement paste composites", Cement \& Concrete Compósites, v. 21, pp.49-57, 1999.

[45] TOLEDO FILHO, R.D., ENGLAND, G.L., GHAVAMI, K., "Comportamento em compressão de argamassas reforçadas com fibras naturais”, Revista Brasileira de Engenharia Agrícola Ambiental, v.1, n.1, pp.79-88, 1997.

[46] SANTOS, D.O.J., FONTES, C.M.A., LIMA, P.R.L., "Uso de agregado miúdo reciclado em matrizes cimentícias para compósitos reforçados com fibras de sisal”, Revista Matéria, v.22, n.1, 2017.

[47] MONTEIRO, S.N., TERRONES, L.A.H., CARVALHO, E.A. et al., "Efeito da interface fibra/matriz sobre a resistência de compósitos poliméricos reforçados com fibras de coco", Revista Matéria, v.11, n.4, pp.395-402, 2006.

[48] MENDES, R.R., Estudo experimental de corpos de prova de concreto com fibras de aço sujeitos à tração por compressão diametral e à tração direta, Dissertação de M. Sc, PUC-Rio, Rio de Janeiro, RJ, Brasil, 2016.

[49] LI, Y., HU, C., YU, Y., "Interfacial studies of sisal fiber reinforced high density polyethylene (HDPE) composites", Composites Part A: Applied Science and Manufacturing, v. 39, n. 4, pp. 570-578, 2008. 
[50] CARVALHO, R.R.C.; CAVALLINI NETO, G., CANDIDO, V.S., "Utilização de fibra de sisal como agente de reforço em matriz cimentícia para fabricação de blocos de concreto", In: 60 Congresso Brasileiro de Cerâmica, pp.1619-1627, Águas de Lindóia, 2016.

[51] TOLEDO FILHO, R.D., FAIRBAIRN, E.M.R., SILVA, F.A., et al., "Durability of compression molded sisal fiber reinforced mortar laminates", Construction \& Building Materials, v. 23, pp. 2409-2420, 2009.

[52] FERREIRA, S.R., LIMA, P.R.L., SILVA, F.A., et al., "Influência de ciclos molhagem-secagem em fibras de sisal sobre a aderência com matrizes de cimento Portland", Revista Matéria, v.17, n.2, pp.1024-1034, 2012.

[53] COLONETTI, L.M., GODINHO, D.S.S., Estudo do efeito da adição de fibras de sisal nas propriedades do concreto, Artigo de Graduação, UNESC, Santa Catarina, SC, 2017.

[54] SANTANA, M.R.O., DOMINGUEZ, D.S., IGLESIAS, S.M., et al., "Modelos de regressão aplicados na caracterização de argamassas leves contendo agregados não convencionais de EVA e fibras de piaçava". Revista Matéria, v. 23, n. 3, 2018.

\section{ORCID}

Leonardo de Souza Dias

Alice Vitória Serafim Beserra

https://orcid.org/0000-0001-5925-2171

Robson Arruda dos Santos

https://orcid.org/0000-0002-2605-7916

André Albino de Sousa

Assis Barbosa de Lira Neto

Aurélia Emanoela de Freitas Gonçalves Landim

Geovany Ferreira Barrozo

https://orcid.org/0000-0001-5615-4365

https://orcid.org/0000-0002-5702-800X

https://orcid.org/0000-0002-1888-4292

https://orcid.org/0000-0003-0107-6624

Cícero Joelson Vieira Silva

https://orcid.org/0000-0003-1893-0735

https://orcid.org/0000-0002-6702-4985 